\title{
The muscle silent period and reciprocal inhibition in man
}

\author{
G. C. AGARWAL AND G. L. GOTTLiEB \\ From the Biomedical Engineering Department, Rush Presbyterian-St. Luke's Medical Center, \\ Chicago, Illinois 60612, and College of Engineering University of Illinois at Chicago Circle, \\ Chicago, Illinois 60680, U.S.A.
}

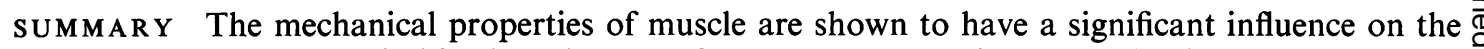
duration of the silent period in the soleus EMG. In contrast to this, the mechanical events have no influence on the duration of the reciprocal inhibition of the anterior tibial muscle. However, a second, delayed cessation of the EMG activity in the anterior tibial muscle is due to mechanical events.

The muscle silent period which follows a twitch contraction, found in the electromyogram (EMG) of man by Hoffmann (1922) is a phenomenon related to several reflex mechanisms which include both direct inhibition of the motoneurone pools and the simultaneous withdrawal of afferent muscle spindle facilitation (Hoffmann, 1922; Merton, 1951; Granit, 1955; Paillard, 1955; Hufschmidt, 1966). The electrical silence of reciprocal inhibition of the antagonist muscle is produced by different mechanisms (Sherrington, 1906; Creed, Denny-Brown, Eccles, Liddell, and Sherrington, 1932; Granit, 1955).Reciprocal inhibition has been demonstrated in cats (Lloyd, 1943) and Hagbarth (1962) and Liberson (1965) have shown its probable presence in man at high stimulus intensities.

In a recent paper (Gottlieb and Agarwal, 1971) we discussed the effects of the voluntary contraction of a stimulated muscle and of its antagonist on the Hoffmann reflex (Hoffmann, 1922). It was shown that the relationship between the amplitude of the electromyographic (H-wave) and mechanical (twitch) components of the Hoffmann reflex may be significantly influenced by the silent period in the agonist muscle and by reciprocal inhibition in the antagonist muscle. The presence of reciprocal inhibition in the anterior tibial muscle with low level stimulation of the tibial nerve was clearly demonstrated. In the present paper we shall discuss the influence of voluntary contraction on both the silent period and on reciprocal inhibition.

\section{METHODS}

Our experiments were performed on five normal male $\dot{\omega}_{\mathrm{G}}$ adults ranging in ages from 21 to 36 years. A subject was seated normally in a chair with his right leg es- N tended, the knee slightly flexed and the foot strapped o to a fixed plate with an attached strain gauge bridg for measuring isometric torque. ${ }^{1}$ The signal from $\vec{T}$ this bridge was also used to provide a visual referenee $\mathbb{D}$ to help the subject maintain a constant foot torque before stimulation. Differential EMG surface electrodes $(1 \mathrm{~cm}$ diameter) were placed on the centre:line of the lower soleus muscle about $3 \mathrm{~cm}$ apart an $20 \mathrm{~cm}$ above the base of the foot, and another pair was placed on the anterior tibial muscle. A ground electrode was placed over the flat surface of the tibia. Cutaneous stimulating electrodes were located posteriorly over the tibial nerve in the popliteal fossa and anteriorly just above the knee. These were held $\stackrel{8}{\mathscr{Q}}$ in place by Velcro straps. All electrodes were coated $\overrightarrow{\vec{O}}$ with Sanborn Redux Creme. The electrical stimuli of 3 $1.5 \mathrm{msec}$ duration were applied from a Grass S-8 $\bar{Z}$ stimulator through an SIU5 isolation unit.

\section{RESULTS}

Figures 1 and 2 show characteristic patterns of the muscle silent period. Figure la shows the silent period in the EMG of the soleus muscle and the resulting twitch at an initial foot torque 0 (IFT) level of $0.9 \mathrm{kgm}$ in plantarflexion. The stimulus is a pure H-reflex and is shown on a different time scale. Figure $1 b$ shows the silent

1 The aluminium foot plate is rigid. However, the contraction is not $N$ perfectly isometric for the elasticity of the muscle and tendon permit a small amount of shortening. It is safe to assume, however, that the $\mathrm{W}$ relationship between measured torque and muscle tension remained $\sigma$ constant and linear during a muscle contraction. 


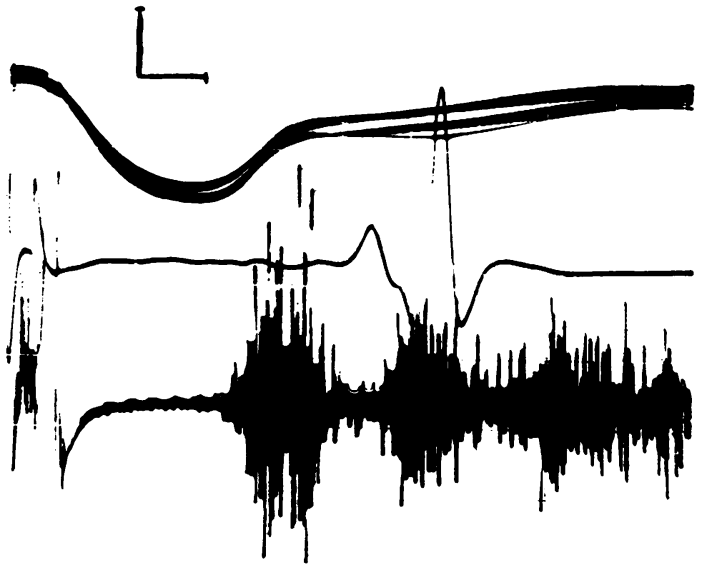

FIG. 1a. Silent period in the soleus muscle after the $H$-wave. Plantar IFT level $0.9 \mathrm{~kg} \mathrm{~m}$. Five traces superimposed. H-wave $0.8 \mathrm{mV} /$ unit at $5 \mathrm{msec} /$ unit time scale, soleus EMG $0.04 \mathrm{mV} /$ unit, twitch torque $0.47 \mathrm{~kg} \mathrm{~m} /$ unit, time $50 \mathrm{msec} /$ unit.

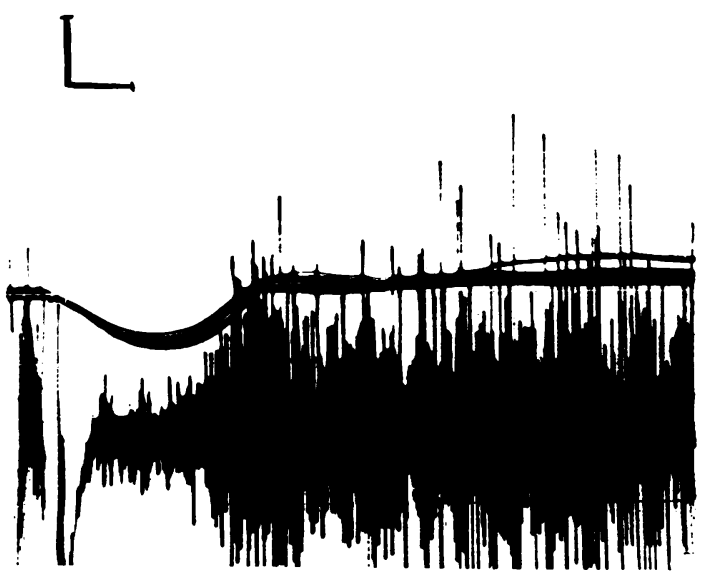

FIG. 2a. Silent period in the soleus muscle after a strong $H$-wave at IFT level of $4.5 \mathrm{~kg} \mathrm{~m}$. Five traces superimposed. Soleus EMG $0.04 \mathrm{mV} /$ unit, twitch torque $0.47 \mathrm{~kg} \mathrm{~m} /$ unit, time $50 \mathrm{msec} /$ unit.

period in the soleus EMG and the resulting twitch at three different levels of IFT in plantarflexion. In this Figure, the IFT is increasing from top to bottom and the stimulus is pure $\mathrm{H}$-reflex. Quite clearly, the break in the silent period occurs after the twitch peak and before the hump in the relaxation phase of the twitch (Creed et al., 1932). Some individual motor units may fire earlier, during the silent period, particularly at higher levels of IFT. This earlier activity within the silent period can indeed be very significant with strong IFT (see Figs $1 \mathrm{~b}$ and $2 \mathrm{a}$ ). The silent period and the subsequent EMG activity in the

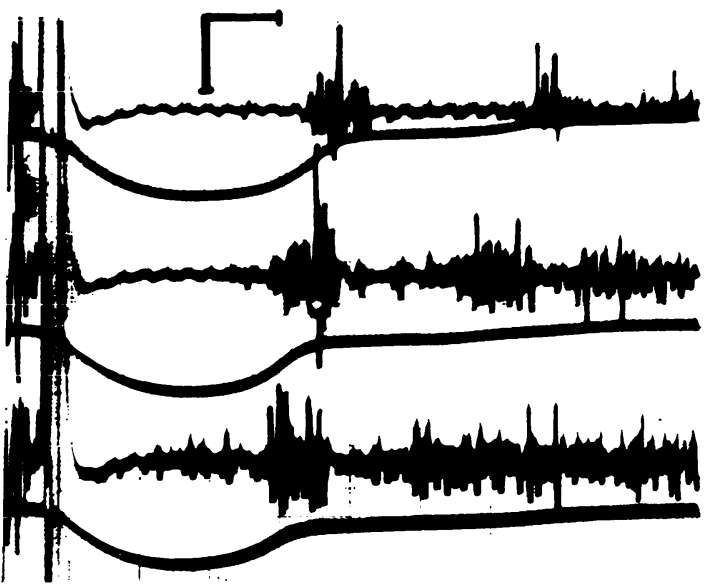

FIG. 1b. Silent period in the soleus muscle after the $H$-wave. Top trace in each of the three responses is the soleus EMG, $0 \cdot 1 \mathrm{mV} /$ unit. Lower trace is the twitch torque, $1 \cdot 2 \mathrm{~kg} \mathrm{~m} /$ unit, at three levels of plantar initial foot torque (IFT) $0 \cdot 9,1 \cdot 8$, and $2 \cdot 7 \mathrm{~kg} \mathrm{~m}$, IFT increasing from top to bottom, time $50 \mathrm{msec} / \mathrm{unit}$.

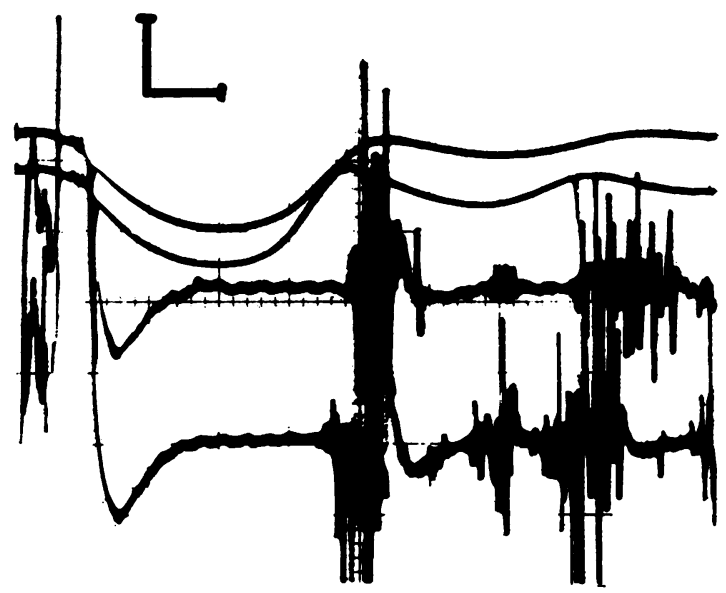

FIG. 2b. Silent period at two levels of plantar IFT 0.47 and $1.1 \mathrm{kgm}$. Twitch torque $1.2 \mathrm{~kg} \mathrm{~m} /$ unit, soleus EMG $0.04 \mathrm{mV} /$ unit, time $50 \mathrm{msec} /$ unit.

soleus is strongly influenced by the time course of the mechanical events-that is, by the muscle twitch. In Fig. 2b, an increase in IFT causes the relaxation phase of the twitch to occur sooner and more rapidly, resulting in a briefer silent period.

Figures 3 and 4 show characteristic patterns of reciprocal inhibition in the anterior tibial muscle. The foot is dorsiflexed by the subject. The IFT in Fig. 3a is $1.92 \mathrm{~kg} \mathrm{~m}$ and the stimulus is near maximal for the H-wave. In Fig. $3 b$ the stimulus 

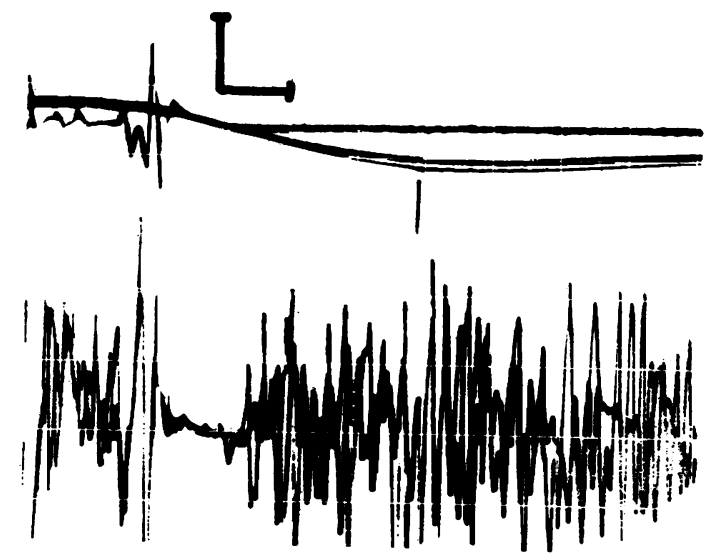

FIG. 3a. Reciprocal inhibition of the anterior tibial muscle by an H-reflex in the soleus muscle. Scales: Soleus $H$-wave $1 \mathrm{mV} /$ unit, dorsal IFT $1.92 \mathrm{~kg} \mathrm{~m}$, twitch torque $1.2 \mathrm{~kg} \mathrm{~m} /$ unit, anterior tibial EMG 0.1 mV/unit, time 20 msec/unit. Two traces superimposed.

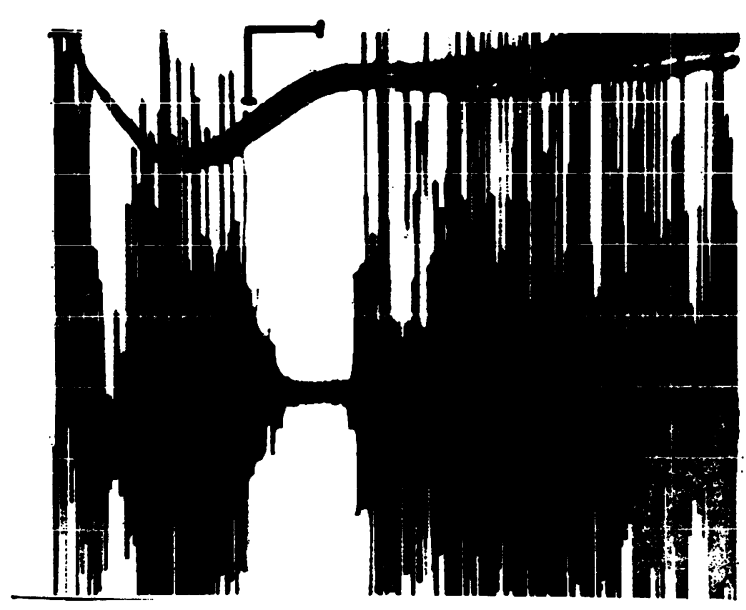

FIG. 4. Reciprocal inhibition. Dorsal IFT $0.72 \mathrm{~kg} \mathrm{~m}$, twitch torque $0.47 \mathrm{~kg} \mathrm{~m} /$ unit, anterior tibial EMG 0.08 mV/unit, time $50 \mathrm{msec} / \mathrm{unit}$. Six superimposed traces.

elicits a near maximal M-wave. Figure 4 shows the EMG activity in the anterior tibial muscle during strong dorsal IFT and with a near maximal M-wave stimulus.

As the foot is more strongly plantarflexed (with the stimulating voltage held constant), the twitch produced by a reflex diminishes (Gottlieb and Agarwal, 1971). There are other changes that may also be observed in the electrical and mechanical behaviour of this twitch. The twitch contractions at three different levels of IFT are superimposed in Fig. 5. The twitch peak occurs

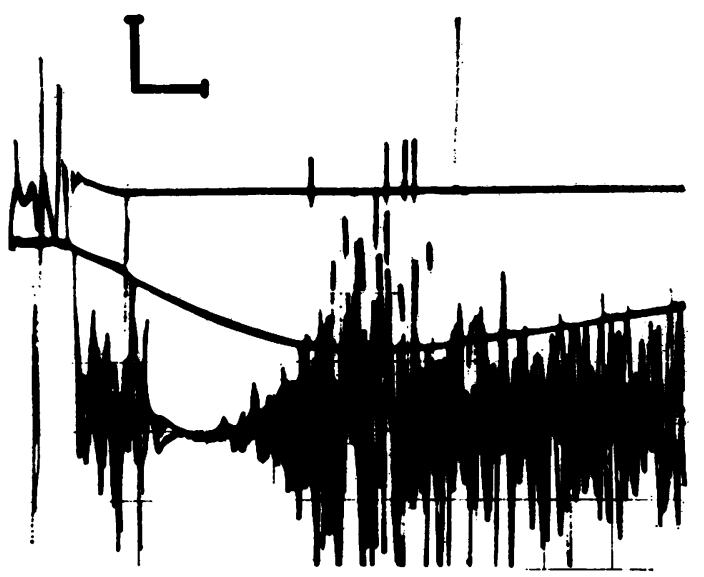

FIG. 3b. Reciprocal inhibition of the anterior tibial के muscle by a $M$-wave stimulus in the soleus. Scales: $\vec{\circ}$ soleus $M$-wave $1 \mathrm{mV} /$ unit, dorsal IFT $1.92 \mathrm{~kg} \mathrm{~m}$, twitch torque $1.2 \mathrm{~kg} \mathrm{~m} /$ unit, anterior tibial EMG 0.1 mV/unit, time 20 msec/unit. Five superimposed traces.

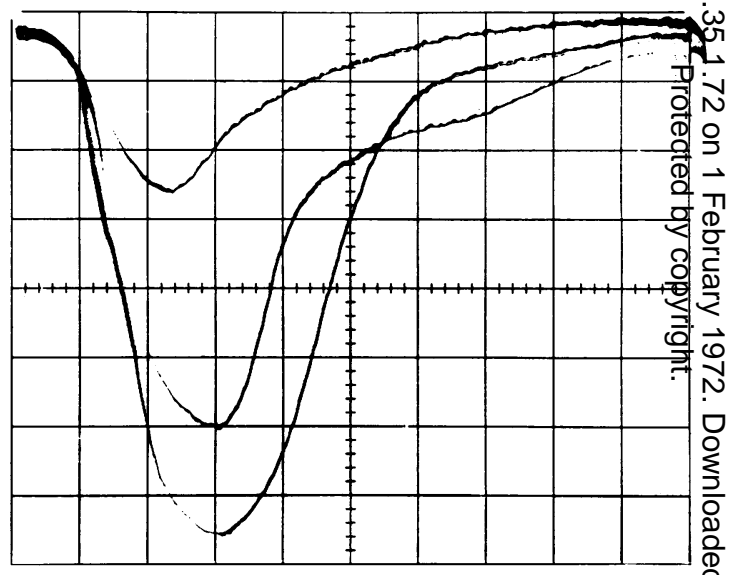

FIG. 5. Twitch torque with constant stimulus voltage at different plantar IFT levels 2,1 , and $0 \mathrm{~kg} \mathrm{~m}$ from top to lowest trace, twitch torque $0.1 \mathrm{~kg} \mathrm{~m} / \mathrm{unit}$, time 50 msec/unit.

earlier as plantar IFT increases as does the hump in the relaxation phase (Agarwal, Berman, Löhnberg, and Stark, 1970). It is also true that as IFT increases in plantarflexion, the peak-to-peak amplitude of the H-wave increases (Paillard, 1955; Gottlieb and Agarwal, 1971). The H-wave amplitude influences more than just the twitch amplitude, for, with increased $\mathrm{H}$-wave amplitude, the twitch peak time is reduced by about $20 \mathrm{msec}$ (Buchthal and Schmalbruch, 1970).

In Fig. $1 b$ the decrease in the duration of the silent period with increasing IFT is as much as $50 \mathrm{msec}$ and is consistently seen in all subjects. 
The cessation of the silent period by a burst of EMG activity during the relaxation phase of the muscle is a mechanically induced event due to restretching of the primary endings of the spindles (Granit, Kellerth, and Szumski, 1966).

The strong mechanical influence of the twitch on the EMG is further shown in Fig. 2b, where a short, second silent period is observed with a clonus-like EMG (Rabending and Koch, 1962). In this Figure, the IFT level is nearly doubled for the lower trace, significantly changing the duration of the silent period as well as subsequent EMG activity.

\section{DISCUSSION}

The pause in the discharge of the spindle primaries during contraction has been accepted as the decisive factor in the explanation of the silent period ever since the work of Fulton and Pi-Suñer (1928), Matthews (1933), Granit and Van der Meulen (1962), Jansen and Rudjord, 1964, and Angel, Eppler, and Iannore (1965). Granit and Van der Meulen (1962) have observed that the duration of the pause of the primaries in contraction varies very little with passive tension and extension. However, the mechanical events in an actively contracted muscle are quite different from those in one that is passively stretched.

These results clearly indicate that the duration of the silent period in man depends on the level of the initial muscle activity. They are consistent with the experiments of Merton (1951), Paillard (1955), and Liberson (1962). However, they are in contradiction to a recent study by Higgins and Lieberman (1968 a, b).

There are, of course, several other factors contributing to the generation of the silent period: Golgi tendon organ inhibition, Renshaw cell inhibition, and the synchronizing effect of simultaneous discharge of the alpha motoneurone pool (Hoff, Hoff, Bucy, and Pi-Suñer, 1934). Although the sensory contributions (spindle and tendon organ) will influence the duration of the silent period, the initiation of the silent period, which immediately follows the H-reflex, must be brought about by the other, purely spinal, phenomena. (The effect of other group I fibres that may be excited by the stimulus is presumably inhibitory but is not accurately known.) That is because the peripheral sensory response cannot begin until the appearance of the $\mathrm{H}$-wave (which initiates the reflex contrac-

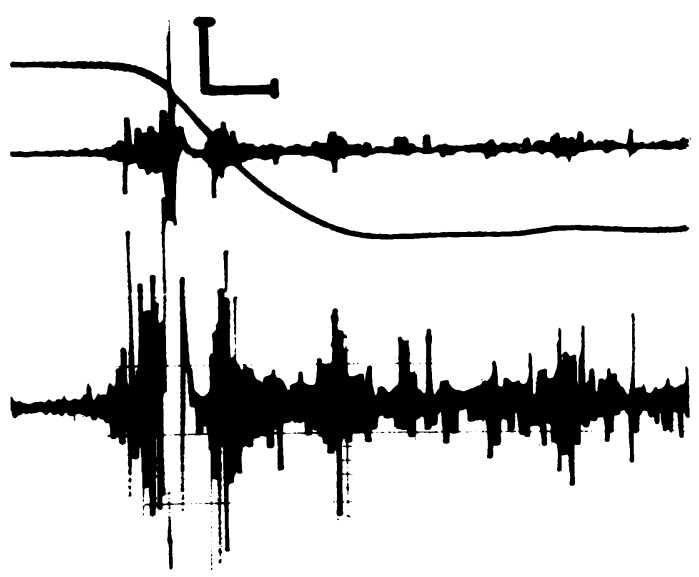

FIG. 6. Silent period after an $H$-wave during rapid contraction. Top trace: plantar foot torque starting from relax position, $1 \mathrm{~kg} \mathrm{~m} / \mathrm{unit}$; middle trace: soleus EMG showing stimulus artefact, $H$-wave, and silent period for about 25-30 msec, $1 \mathrm{mV} /$ unit; bottom trace: same as middle trace, $0 \cdot 2 \mathrm{mV} /$ unit; time $50 \mathrm{msec} /$ unit.

tion), and the sequelae cannot be manifest in the EMG for the $30 \mathrm{msec}$ it takes for information to circumnavigate the reflex arc. The immediate spinal effects of a synchronized motor discharge are a hyperpolarization of recently fired motoneurones which is reinforced by an inhibitory volley from the Renshaw cells. In the example in Fig. 6 the gastrocnemius-soleus muscle group is contracting rapidly at the time when the H-reflex is elicited. The strong EMG activity continues during the interval between the electrical stimulus and the $\mathrm{H}$-wave, and is suddenly interrupted for a period of about $25-30 \mathrm{msec}$. Because of the vigorous voluntary contraction, there is no effective twitch but a brief inhibition is still produced by spinal mechanisms alone.

Whereas the duration of the silent period is related to contractile events and is terminated by an EMG burst due to restretching of the spindles, the observed duration of reciprocal inhibition (about $30 \mathrm{msec}$ ) is independent of muscular activity and remains constant with changes of IFT in dorsiflexion. The inhibition appears from the instant that the $\mathrm{H}$-wave is observed in the soleus muscle. This time of onset is unaltered even when the stimulus is large enough to block antidromically the $\mathrm{H}$-wave in the soleus muscle. This constancy occurs because reciprocal inhibition is due to the orthodromic Ia fibre volley in the tibial nerve which inhibits the motoneurone pool of its antagonist muscle. The duration of this inhibition is comparable with that 
appearing in the contracting soleus muscle in Fig. 6. Such a similarity is not unexpected since both silences are produced by spinal rather than peripheral influences.

An interesting observation in relation to reciprocal inhibition in the anterior tibial muscle may be made in Fig. 4. A $50 \mathrm{msec}$ pause in the EMG activity is observed at the hump in the twitch, induced by the mechanical events of that twitch. Just before the hump, the gastrocnemiussoleus muscle is in its relaxation phase which permits restretching of the gastrocnemius-soleus spindles. The induced activity in afferent Ia nerve fibres from the gastrocnemius-soleus primary spindle endings has an inhibitory influence on the motoneurone pool of the anterior tibial muscle. At the same time the spindles of the anterior tibial muscle are shortening. These two factors together produce the observed cessation of the EMG activity in the anterior tibial muscle.

Excitation of primary spindle afferent fibres from the gastrocnemius and soleus muscles may produce a period of electrical silence on both homonymous and antagonistic muscle groups. The silence of the antagonist is due to reciprocal inhibition over neural pathways within the spinal cord. The homonymous silence is also initiated by spinal mechanisms but the extended duration of this silence is determined by mechanical factors of the contracting muscle.

This work was partially supported by NSF grant GK-17581 and NIMH grant MH-8396.

\section{REFERENCES}

Angel, R. W., Eppler, W., and Iannone, A. (1965). Silent period produced by unloading of muscle during voluntary contraction. Journal of Physiology (London), 180, 864-870.

Agarwal, G. C., Berman, B. M., Löhnberg, P., and Stark, L. (1970). Studies in postural control systems. Part II : Tendon jerk input. IEEE Transactions on Systems Science and Cybernetics, SSC-6, 122-126.

Buchthal, F., and Schmalbruch, H. (1970). Contraction times of twitches evoked by H-reflexes. Acta Physiologica Scandinavica, 80, 378-382.

Creed, R. S., Denny-Brown, D., Eccles, J. C., Liddell, E. G. T., and Sherrington, C. S. (1932). Reflex Activity of the Spinal Cord. Clarendon Press: Oxford.

Fulton, J. F., and Pi-Suñer, J. (1928). A note concerning the probable function of various afferent end-organs in skeletal muscle. American Journal of Physiology, 83, 554-562.
Gottlieb, G. L., and Agarwal, G. C. (1971). Effects of initial conditions on the Hoffmann reflex, Journal of Neurology, Neurosurgery, and Psychiatry, 34, 226-230.

Granit, R. (1950). Reflex self-regulation of muscle contraction and autogenetic inhibition. Journal of Neurophysiology, 13, 351-372.

Granti, R. (1955). Receptors and Sensory Perception. Yale University Press: New Haven.

Granit, R., Kellerth, J.-O., and Szumski, A. J. (1966). Intracellular autogenetic effects of muscular contraction on extensor motoneurones. The silent period. Journal of Physiology (London), 182, 484-503.

Granit, R., and Van der Meulen, J. P. (1962). The pause during contraction in the discharge of the spindle afferents from primary end organs in cat extensor muscles. Acta Physiologica Scandinavica, 55, 231-244.

Hagbarth, K.-E. (1962). Post-tetanic potentiation of myotatic reflexes in man. Journal of Neurology, Neurosurgery, and Psychiatry, 25, 1-10.

Higgins, D. C., and Lieberman, J. S. (1968a). The muscle silent period: variability in normal man. Electroencephalography and Clinical Neurophysiology, 24, 176-182.

Higgins, D. C., and Lieberman, J. S. (1968b). The muscle silent period and spindle function in man. Electroencephalography and Clinical Neurophysiology, 25, 238-243.

Hoff, H. E., Hoff, E. C., Bucy, P. C., and Pi-Suñer, J. (1934). The production of the silent period by the synchronization of discharge of motor neurones. American Journal of Physiology, 109, 123-132.

Hoffmann, P. (1922). Untersuchungen über die Eigenreflexe (Sehnenreflexe) Menschlicher Muskeln. Springer: Berlin.

Hufschmidt, H.-J. (1966). The demonstration of autogenic $\rightarrow$ inhibition and its significance in human voluntary move- 0 N ment, in Muscular Afferents and Motor Control, Proceed- $\vec{\Phi}$ ings of the First Nobel Symposium, 1965, Södergarn. $\stackrel{?}{\square}$ pp. 269-274. Edited by R. Granit. Almqvist and Wiksell: Stockholm.

Jansen, J. K. S., and Rudjord, T. (1964). On the silent period and Golgi tendon organs of the soleus muscle of the cat. Acta Physiologica Scandinavica, 62, 364-379.

Liberson, W. T. (1962) Monosynaptic reflexes and their clinical significance, in Progress in Electromyography Electroencephalography and Clinical Neurophysiology, Suppl. No. 22, 79-89.

Liberson, W. T. (1965). Experiment concerning reciprocal inhibition of antagonists elicited by electrical stimulation of agonists in a normal individual. American Journal of Physical Medicine, 44, 306-308.

Lloyd, D. P. C. (1943). Conduction and synaptic transmission of the reflex response to stretch in spinal cats. Journal of Neurophysiology, 6, 317-326.

Matthews, B. H. C. (1933). Nerve endings in mammalian muscle. Journal of Physiology (London), 78, 1-53.

Merton, P. A. (1951). The silent period in a muscle of the human hand. Journal of Physiology (London), 114, 183-198.

Paillard, J. (1955). Réflexes et Régulations D'Origine Proprioceptive chez L'Homme. Arnette: Paris.

Rabending, G., and Koch, R. D. (1962). Influence of the amplitude of monosynaptic reflexes on the duration of the silent period, in Progress in Electromyography. Electroencephalography and Clinical Neurophysiology, Suppl. No. 22, 120-121.

Sherrington, Sir C. S. (1906). The Integrative Action of the Nervous System, Yale University Press: New Haven. (Paperbound: 1961.) 